\title{
The efficacy of 4Cs-based reading to foster 21st-century learning competencies
}

\author{
David Imamyartha, Siti Masrifatul Fitriyah, Zakiyah Tasnim, Areta Puspa, Aan Erlyana \\ Fardhani, Eka Wahjuningsih, Siti Sundari, Rizki Febri Hudori, and Bambang Arya \\ Department of English Education, Faculty of Teacher Training and Education, Jember University, Kalimantan 10, \\ Krajan Timur, Sumbersari district, Jember regency, East Java, Indonesia
}

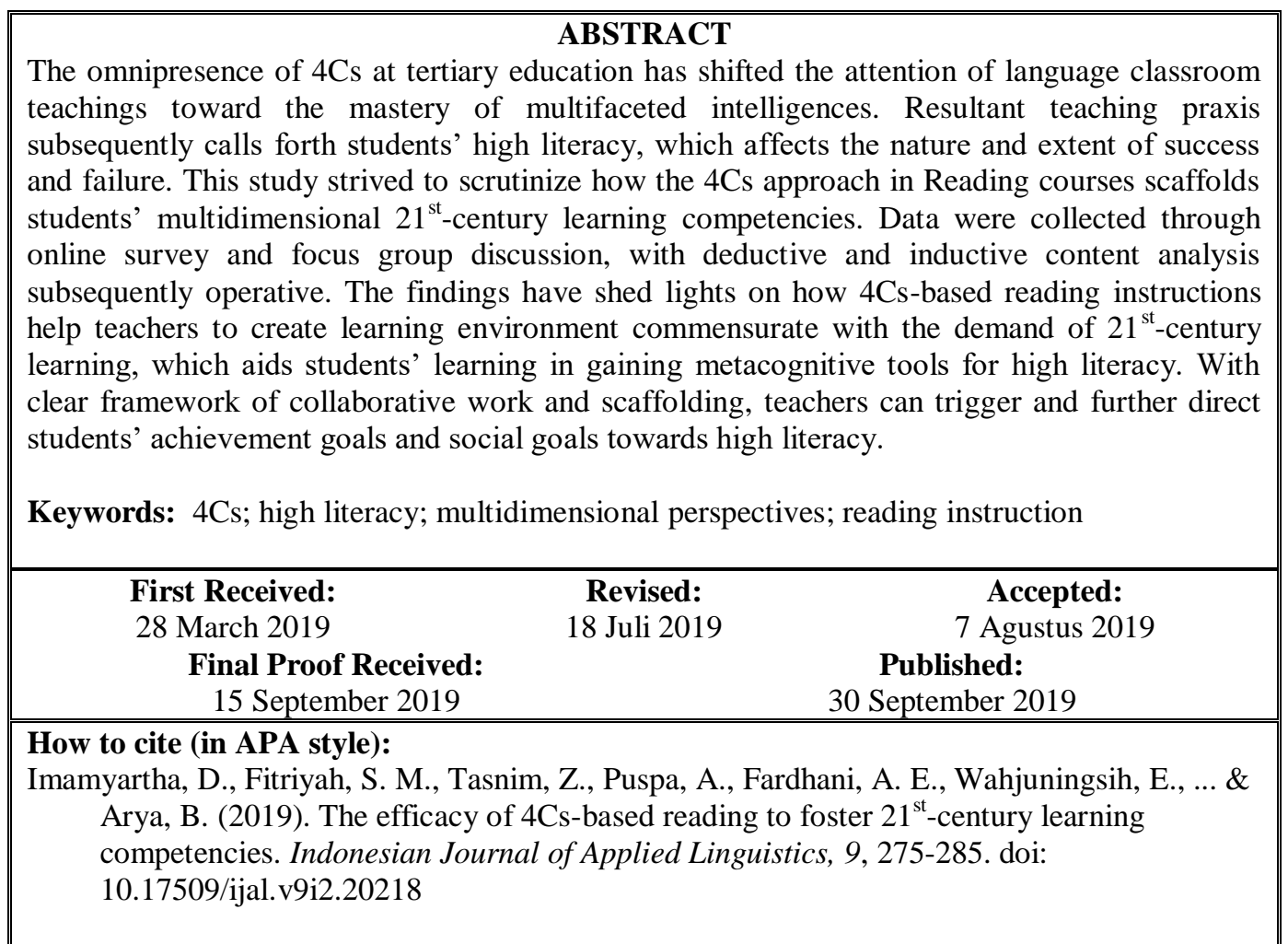

\section{INTRODUCTION}

To date, a wide array of teaching methodologies have been implemented into Indonesian EFL classes at tertiary education as an endeavor for the creative and innovative. These attempts take issues with the current educational reforms which require students to be knowledgeable and productive across distinctive academic milieus to create new knowledge and novel artifacts of high value to others (Bereiter \& Scardamalia, 2006; Bransford, Brown, \& Cocking, 2005). This initiative complies with the notion of high literacy, which is deemed as the ability to employ content knowledge, language competence, and reasoning in ways pertinent to distinctive disciplines and circumstances (Applebee, Langer, Nystrand, \& Gamoran, 2003). If the success in high literacy-laden academic setting is a focal education goal, learners need to be capable of critical reading and effective writing as well as talking about what they have read and experienced. As such, acquiring critical reading, writing, and discursive collaboration constitute the crux of current educational odyssey (Alfassi, 2009).Skillful reading and writing are sophisticated cognitive processes which involve meaning-making and monitoring of understanding (Smagorinsky, 2001). To gain comprehension, they need to create a model or explanation which organizes information extracted from text in ways logical to them and commensurate with their schemata. This infers active reader who employs existing knowledge and novel knowledge as well as flexible use of strategies to construct meaning as an attempt to empower, monitor, and support comprehension (Alexander \& Jetton, 2000). Put simply, literacy learning calls forth strategy instruction aimed at

\footnotetext{
* Corresponding Author

Email: david.fkip@unej.ac.id
} 
fostering students' conscious control over their cognitive processes (Pressley, 2000).

This work is projected to propose an alternative method for reading instruction by examining the efficacy of the 4Cs approach (communication, collaboration, critical thinking, and creativity). There are five characteristics commonly evident in English reading class in Indonesia (Cahyono \& Widiati, 2006). First, teachers tend to see the learning process as the discovery of truth in bottled instruction. Secondly, students are premised to compete against their counterparts, rather than taking part in dialogic learning. As such, students' collaboration is of no value, and as a corollary they are attached to grappling with low-order thinking tasks. Thirdly, teachers heavily depend on existing teaching resources, which results in confined teaching as what is presented is strictly aligned with their teaching resources. Fourthly, teachers commonly act as 'the sage on the stage' by which they disseminate knowledge and require their students to identify the facts of knowledge.

More specifically, the present study is aimed at scrutinizing the impact of reading classes oriented to 4Cs approach on the multidimensional students' perspectives, as formulated in the following research questions: a) what are the overall profiles of multidimensional students' learning processes actualized in 4Cs reading instruction? b) what are the significant predictors among the components of multidimensional learning processes which contribute to knowledge creation self-efficacy in 4Cs reading instruction? and c) what are the students' voices on their multidimensional learning processes in $4 \mathrm{Cs}$ reading instruction?

Rationalizing 4Cs approach in transactional reading The 4Cs approach to teaching reading under investigation is grounded within three foundations, comprising of epistemological basis, psychological basis, and theoretical basis. The epistemological bedrock of 4Cs approach stems from the epistemological ambivalence between the traditional epistemology and the socio-constructivist epistemology. The traditional epistemology views knowledge as objective entity, while the socio-constructivist perspective views knowledge as a joint subjective understanding. One prominent proponent to such constructivist-based view is the Immanuel Kant, as explicated in his book 'Critique of Pure Reason' (1998). He argued that both the nature and boundary of our knowledge is not capable of discovering the evidence of knowing, that is knowing germane to how to create something unless we see our mind and its objects as separated constructs. Put simply; we can ascertain that everything which is susceptible to being experienced is arranged in this fashion.

From psychological facets, Piaget's (1976) explicates that knowledge development portrays one's construction attempted by learner's understanding in tandem with peers. He further explains that knowledge changes as past experience signifies both recurring development and reorganization. Vygotsky (1978) posits that a learner develops speech performance and thinking separately. Thoughts are spoken and continuously reshaped as speech sustains mental dynamics. The social environment is crucial to learner's development for it can either propel or obstruct the increment of knowledge. Vygotsky's framework of zone of proximal development (ZPD) explains that no single ZPD exists among learners inasmuch as the zone tremendously varies with regard to experience, culture, and society. If ZPD is expected to develop, a joint endeavor has to be taken prior to learning, through which learners' collaboration is needed for cognitive development.

To sum up, this work views 4Cs approach from three theoretical assumptions which differentiate 4Csbased learning from other learning experiences. Firstly, students' learning represents active constructive process in collaboration. Secondly, teaching is concerned with supporting learners' constructive process of understanding, not imparting information to learners. Thirdly, teaching constitutes learning-teaching concept, instead of teaching-learning notion. The socioconstructivist foundation to the approach may well be accounted by the SCCS learning theory by Sontag (2009). This approach includes social-connectedness and cognitive-connectedness schemata. The socialconnectedness scheme drives and is governed by the competence and desire to collaborate with others. This scheme undergirds the ability to generate and maintain physical, digital, hybrid social connection (Oblinger \& Oblinger, 2005). The cognitive-connectedness schema determines students' ability and initiative to understand the connection between what they have acquired and the more comprehensive picture of their prior knowledge. The changes in this schema have allowed today's students to view knowledge as something indexing the world and sophisticatedly constituting driven by activities and contexts in which it is created (Brown, Collins, \& Duguid, 1989).

\section{Multidimensional students' perceptions}

A number of international organizations have embarked on developing frameworks to formulate the learning praxis typical of 21 st-century education. Setting the bedrock for this study, Chai, Koh, Deng, Tsai, and Tsai's survey (2015) unraveled students' experience in 21-century-learning practices and portrayed the interlinks among the practices. Their study is fundamental initiative in response to the educational demands echoed by the partnership for the 21st century skills (P21CS, 2009), the National Educational Technology Standards (NETS) (ISTE, 2013), Assessment and Teaching of Twenty-First-Century Skills (Griffin, MacGaw, \& Care, 2012), and TwentyFirst-Century Skills and Competences for new Millennium Learners (OECD, 2005). These initiatives have led to an edifice of constructs constituting the essential competencies for the 21 st-century education, 
which include escalating students' learning through information and communication technology (ICT) and collaborative inquiry coupled with communication. Most of the existing frameworks (such as P21CS, 2009; ISTE, 2013) put emphasis on the essential of engaging learners in critical thinking, creative thinking, and authentic problem-solving tasks.

Due to the rapid socioeconomic change and technology landscaping, the aforementioned competencies have gained more importance (Silva, 2009) when viewed against the education praxis laden with passive learning. Chai et al. (2015) made substantial contribution to research on 21 st-century education by developing a questionnaire on multidimensional students' perceptions of 21 st-century learning. Their study premises the importance of added competencies in addition to the abovementioned skills. Their study garnered students' perceptions on such skills as creative thinking CreT), critical thinking (CriT), knowledge creation self-efficacy (KCE), meaningful learning with ICT (MLT), self-directed learning SDL), collaborative learning (CoL), and authentic-problem solving (APS). These components of learning praxis can be classified into two groups, including learning processes and higher-order thinking process.

Chai et al. (2015) premise that the learning for 21st-century education should engage students in collaborating-to-learn and learning-to-learn, which holds students' active role and responsibility for their own learning, objectives, and plan for their progress, as well as monitoring and awareness of their progression (Garrison, 1992). These constructs refer to selfregulated learning (see Zimmerman, 2008, for overview). Within this construct, students choose and operationalize learning strategies toward gaining their individualized learning objectives and at the same time adaptive to the extent of success or failure. Another component is collaborative learning, which engages learners in community-based learning.

The other piece of twenty-first-century competence is pertinent to the edifice of creative thinking, critical thinking, and authentic problemsolving. Critical thinking is concerned with the ability to analyse issues, evaluate ideas and arguments, make apt decisions, and offer a solution (Elder \& Paul, 1994). Although students have attained critical thinking, the absence of creative thinking is generally socioculturally unacceptable, nor is it supportive and productive to collaborative learning. In this respect, creative thinking manifests the ability to generate work which is both original and relevant, that is satisfying tasks constrain (Sternberg \& Lubart, 1996, as cited in Chai et al., 2015). These represent complex and vague issue, thus calling for learners' consent on what represents acceptable solutions with possible alternatives (Jonassen, 2000). The intertwinement amongst critical thinking, creative thinking, and authentic problem-solving fosters learners to surmount cognitively demanding problems, helping them to develop competencies for the 21st-century education (Chai et al., 2015).

\section{METHOD \\ Design}

The study strived to fill both empirical and methodological voids in the studies on 4C in English learning. The existing works on multidimensional students' perceptions of 21 st-century education are lacking. From methodological stance, this study attempted to push the boundary by operationalizing focus group discussion to the myriads of statistically grounded studies on the very area. The instructional activities bound to 4Cs include numerous activities attending to each $\mathrm{C}$. Instead of treating each $\mathrm{C}$ as separate process, the instruction involves each $\mathrm{C}$ in an overlapping fashion throughout a single meeting. Every lesson is conducted by starting from communication, collaboration, critical thinking, to creativity. Creativity is put at the lesson finale as the fundamental objective of 4Cs approach is knowledge creation (Chai et al., 2015). The following figure explains the sequential framework of $4 \mathrm{Cs}$ approach to the reading instructions.

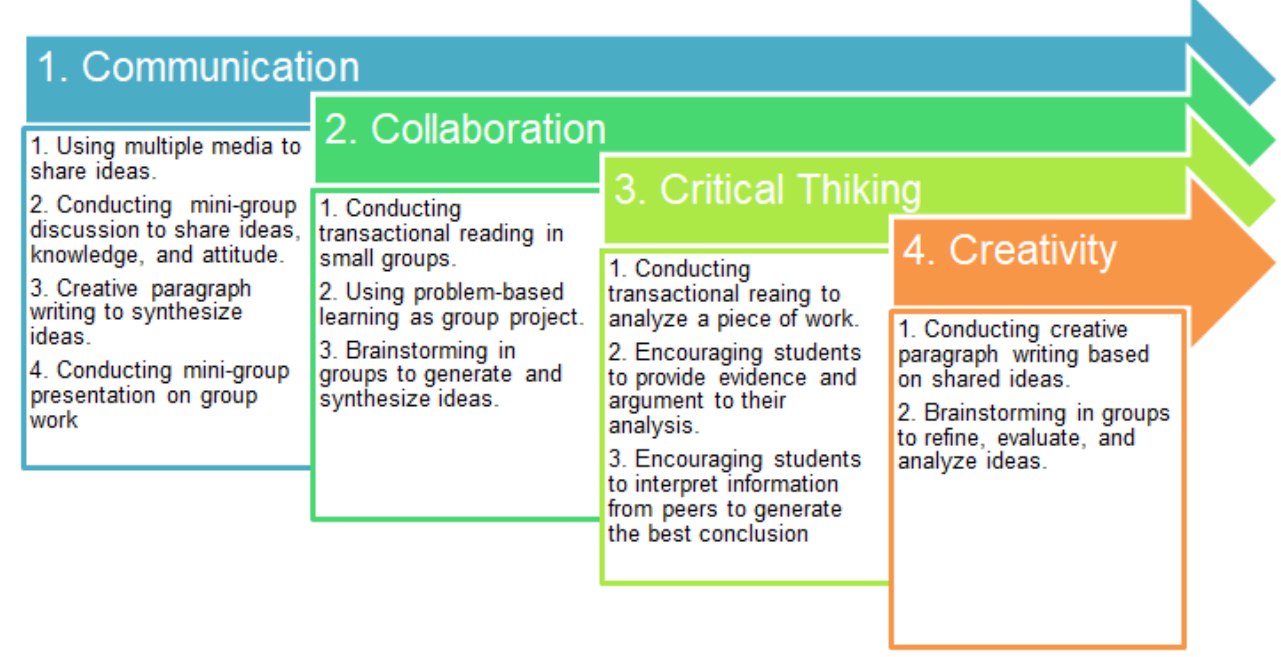

Figure 1. Sequential framework of instructional procedure 


\section{Participants}

The participants were purposively chosen by involving those enrolled in two Intensive Reading classes and two Critical Reading classes as these classes were aimed at excelling reading skills relevant to 4 Cs. In total, 160 students from the classes were involved in the online survey, but only 113 students responded to the survey. This accomplishment level may be attributed to the fact the classes were already over during the research, thus limiting the accessibility to gain a potentially huge number of responses. These students were enrolled in English education program, comprising of freshmen and sophomores. Despite different foci, the lecturers applied 4Cs approach in their respective classes.

\section{Data instrumentation and analysis}

The questionnaire proposed by Chai et al. (2015) was operative to probe multidimensional students' learning processes grounded within $4 \mathrm{C}$ approach in reading instructions. This survey has been validated through principal component analysis (PCA) and confirmatory factor analysis (CFA). The 32-item questionnaire also exceeded the cut off values of factor loading (0.50), composite reliability (0.70), and average variance extracted (0.50). What is more, acceptable model fit was identified for the survey: $\mathrm{v}=1.92, \mathrm{df}=13, \mathrm{v} 2 / \mathrm{df}=1.23$ $(<3.0)$, AGFI $=0.91([0.90)$, TLI $=0.96([0.95)$, CFI $=$
0.98 ([0.95), RMSEA $=0.048 \quad(<0.07)$, indicating acceptable convergent and construct validity of survey item (Chai et al., 2015).

Descriptive statistics was operative to investigate mean and standard deviation across components of multidimensional learning processes (see Table 1). Pearson correlation test was included to see the magnitude of correlation among the dimensions. In addition, One sample t-test also came into play to find out possible significant differences among the components. To find out which component posed significant bearing to the entirety of multidimensional learning processes, multilinear regression analysis was also carried out. Focus group discussion (FGD) involving 10 students was conducted to examine students' multidimensional perceptions. Aimed at identifying patterns and developing finding themes, Braun and Clarke's (2006) thematic analysis was operative upon analyzing the data from the FGD. The analysis strove to thematize recurring meanings and report themes or patterns from data (Braun \& Clarke, 2006). It involved familiarization with the data, generating codes, identifying the themes relevant to research questions among codes, reviewing common themes, defining the themes, and composing a final report.

Table 1. Descriptive statistics on individual dimension of multidimensional learning processes

\begin{tabular}{|c|c|c|c|c|c|c|}
\hline & $\mathbf{N}$ & Minimum & Maximum & Mean & Std. Deviation & Variance \\
\hline SDL1 & 113 & 1.00 & 5.00 & 3.9381 & .78243 & .612 \\
\hline SDL2 & 113 & 1.00 & 5.00 & 4.0265 & .76134 & .580 \\
\hline SDL3 & 113 & 2.00 & 5.00 & 3.9027 & .80139 & .642 \\
\hline SDL4 & 113 & 1.00 & 5.00 & 3.8938 & .85943 & .739 \\
\hline SDL5 & 113 & 1.00 & 5.00 & 3.9912 & .85037 & .723 \\
\hline MLT1 & 113 & 1.00 & 5.00 & 3.4336 & 1.10094 & 1.212 \\
\hline MLT2 & 113 & 1.00 & 5.00 & 3.3097 & 1.00071 & 1.001 \\
\hline MLT3 & 113 & 2.00 & 5.00 & 3.7965 & .92736 & .860 \\
\hline MLT4 & 113 & 1.00 & 5.00 & 3.9027 & 1.02613 & 1.053 \\
\hline MLT5 & 113 & 2.00 & 5.00 & 4.4336 & .71808 & .516 \\
\hline CoL1 & 113 & 2.00 & 5.00 & 4.2655 & .77940 & .607 \\
\hline CoL2 & 113 & 2.00 & 5.00 & 4.1504 & .75854 & .575 \\
\hline CoL3 & 113 & 3.00 & 5.00 & 4.3186 & 67169 & .451 \\
\hline CoL4 & 113 & 2.00 & 5.00 & 4.2655 & .74424 & .554 \\
\hline CoL5 & 113 & 1.00 & 5.00 & 3.8319 & .87528 & .766 \\
\hline CriT1 & 113 & 2.00 & 5.00 & 3.9646 & .76683 & .588 \\
\hline CriT2 & 113 & 1.00 & 5.00 & 4.0796 & .84665 & .717 \\
\hline CriT3 & 113 & 3.00 & 5.00 & 4.0088 & .67474 & .455 \\
\hline CreT1 & 113 & 1.00 & 5.00 & 3.8053 & .82222 & .676 \\
\hline CreT2 & 113 & 1.00 & 5.00 & 3.7168 & .82882 & .687 \\
\hline CreT3 & 113 & 1.00 & 5.00 & 3.6460 & .83367 & .695 \\
\hline CreT4 & 113 & 2.00 & 5.00 & 3.8319 & .81177 & .659 \\
\hline APS1 & 113 & 1.00 & 5.00 & 3.7257 & .83717 & .701 \\
\hline APS2 & 113 & 2.00 & 5.00 & 4.0000 & .85565 & .732 \\
\hline APS3 & 113 & 1.00 & 5.00 & 3.9115 & .88194 & .778 \\
\hline APS4 & 113 & 1.00 & 5.00 & 3.8053 & .93406 & .872 \\
\hline APS5 & 113 & 1.00 & 5.00 & 3.8673 & .83990 & .705 \\
\hline KCE1 & 113 & 2.00 & 5.00 & 3.8584 & .80030 & .640 \\
\hline KCE2 & 113 & 2.00 & 5.00 & 3.9115 & .77411 & .599 \\
\hline KCE3 & 113 & 2.00 & 5.00 & 4.0265 & .76134 & .580 \\
\hline $\mathrm{KCE} 4$ & 113 & 2.00 & 5.00 & 3.9292 & .72846 & .531 \\
\hline KCE5 & 113 & 1.00 & 5.00 & 3.8142 & .82968 & .688 \\
\hline Average & 113 & 2.47 & 5.00 & 3.9185 & .53554 & .287 \\
\hline Valid N (listwise) & 113 & & & & & \\
\hline
\end{tabular}




\section{FINDINGS AND DISCUSSION}

The profiles of multidimensional students' learning processes actualized in $4 \mathrm{Cs}$ reading instruction

The learners have reported the deployment of different dimensions of the learning process through the online survey. This is corroborated by the students' voices on the sense of achievable goals, collaborative works, positive emotion, critical thinking, creative learning, problem-solving skills, self-directed learning, intercultural communication, and knowledge creation self-efficacy. The analyses in Table 2 set the foundation for further understanding the efficacy of 4Cs approach in reading.
The total average scores of multidimensional learning processes of all students $(n=113)$ attained the value $(\mathrm{M}=3.9185, \mathrm{SD}=.53554)$. The overall descriptive data demonstrates that reading instruction has indeed encouraged the students to actively engage in 21stcentury learning processes, concomitantly activating creativity, criticality, and problem-solving. In general, the average total scores in each component also indicate convincing actualization of $4 \mathrm{C}$ skills triggered by the reading instruction. The following table shows the average scores corresponding to each dimension of multidimensional learning.

Table 2. Descriptive statistics on individual dimension of multidimensional learning processes

\begin{tabular}{lcccccc}
\hline & N & Minimum & Maximum & Mean & Std. Deviation & Variance \\
\hline Average CoL & 113 & 3 & 5 & 4.1664 & 0.59095 & 0.349 \\
Average CriT & 113 & 2 & 5 & 4.0177 & 0.71247 & 0.508 \\
Average SDL & 113 & 1.2 & 5 & 3.9504 & 0.62251 & 0.388 \\
Average KCE & 113 & 2.4 & 5 & 3.908 & 0.64422 & 0.415 \\
Average APS & 113 & 1.8 & 5 & 3.8619 & 0.68509 & 0.469 \\
Average MLT & 113 & 2.2 & 5 & 3.7752 & 0.72118 & 0.52 \\
Average CreT & 113 & 2 & 5 & 3.75 & 0.70474 & 0.497 \\
\hline Valid N & 113 & & & & & \\
(listwise) & & & & & & \\
\hline
\end{tabular}

The 4Cs approach to reading instructions have substantially amplified multidimensional 21st-century learning experiences. Even minimum actualization of Cs-based activities in the instruction has created positive classroom atmosphere supportive to the learning of high literacy. With students reporting both extensive and intensive multidimensional learning processes, the instructions are proven fundamental to developing their high literacy due to the involvement of critical thinking, creativity, collaboration, and integrated language learning, compared to segregated reading instruction. As can be seen in Table 3, the magnitude of
4Cs actualization manifests the deployment of collaborative learning and higher-order thinking skills undergirding the learning experience, which apparently portrays both academic goals and social goals. Urdan and Maehr (1995) point out that students' academic goals are the academic goals for success within academic milieu, while social goals are perceived as the social motives driving the endeavour for achievement in an academic situation. Although these two goals may be inherently different, their contribution to students' motivation and performance is not necessarily conflicting (Dowson \& McInerney, 2003).

Table 3. Correlations among dimensions

\begin{tabular}{llccccccc}
\hline & & $\begin{array}{c}\text { Average } \\
\text { KCE }\end{array}$ & $\begin{array}{c}\text { Average } \\
\text { SDL }\end{array}$ & $\begin{array}{c}\text { Average } \\
\text { MLT }\end{array}$ & $\begin{array}{c}\text { Average } \\
\text { CoL }\end{array}$ & $\begin{array}{c}\text { Average } \\
\text { CriT }\end{array}$ & $\begin{array}{c}\text { Average } \\
\text { CreT }\end{array}$ & $\begin{array}{c}\text { Average } \\
\text { APS }\end{array}$ \\
\hline \multirow{6}{*}{ Pearson } & Average KCE & 1.000 & .605 & .443 & .652 & .521 & .678 & .629 \\
& Average SDL & .605 & 1.000 & .512 & .588 & .605 & .713 & .645 \\
Correlation & Average MLT & .443 & .512 & 1.000 & .389 & .523 & .409 & .555 \\
& Average CoL & .652 & .588 & .389 & 1.000 & .556 & .547 & .569 \\
& Average CriT & .521 & .605 & .523 & .556 & 1.000 & .630 & .705 \\
& Average CreT & .678 & .713 & .409 & .547 & .630 & 1.000 & .748 \\
& Average APS & .629 & .645 & .555 & .569 & .705 & .748 & 1.000 \\
\hline
\end{tabular}

In addition to confirmed actualization of multidimensional learning experiences, the study has found that every single dimension is significantly correlated to one another, given p-value marked at 0.000 as shown in Table 3. The overall magnitude of correlation indicates that each dimension is interdependent and implies that the more KCE students achieve, the more multidimensional learning processes take place. With regard to Kim's (2016) study, students engaged in knowledge creation, which is laden with both cognitive and metacognitive processes, are likely to possess more intellectual and linguistic values. Yamashita (2007) mentions that intellectual value includes the perceptions germane to advantages from accessing myriads of information, new ways of thinking, and numerous other values, which can be obtained through taking part in 4Cs-based activities. By contrast, linguistic value, assumedly triggering each facet of multidimensional learning, includes such perceptions as the benefits for learning new words, improvement of reading ability, and language awareness. 
Regardless of the significant correlation among dimensions, the analysis reveals interesting findings concerning MLT. Compared to other dimensions, it demonstrates the weakest correlation with the other dimensions, including KCE. To some extent, it implies that the involvement of ICT in the reading instruction has yet to reach its utmost. Assumedly, this may result from the minimum use of ICT in the class. Throughout the three meetings across three classes, only common devices are operative, mostly limited to teacher's computer and projector. With the recent works highlighting the power of technology-enhanced shared reading, it is very likely that MLT can be escalated to further support KCE. Previous studies have portrayed that technology in shared reading aids in scaffolding critical thinking, creativity, collaboration, and high literacy connected to the other language domains (see Bromley et al., 2014; Gill \& Islam, 2011, for example). Inasmuch as 4Cs approach to reading accords teachers with flexibility in involving various collaborative learning and technologies, MLT is supposed to be equally contributive to KCE and positively influential to other facets of multidimensional learning. Given comprehensive correlation among dimensions, the analysis delved further into examining the explanatory power of bi-domain of multidimensional learning, that is learning process and thinking process.

\section{The predictor to knowledge creation self-efficacy in 4Cs reading instruction}

Prior to the first multilinear regression analysis, One sample t-test was carried out to find out the possible difference between AveLP (average learning processes) and AveTP (average thinking processes). The analysis result indicated that both domains were significantly different, as evinced by p-value marked at 0.000 for both domains. This difference urged the need for the initial multilinear regression analysis on both domains.

There were two stepwise multilinear regression analyses conducted. The first analysis focused on investigating the explanatory power of learning process domain and thinking process domain toward KCE. The first analysis demonstrated that at least one of the domains constituted useful predictor of KCE. This was indicative of the coefficient of multiple determinations marked at 0.733 , which points out that $73.3 \%$ of $\mathrm{KCE}$ is attributed to these domains. ANOVA also acknowledges the explanatory power of the domains. This is indicative of p-value below $\alpha(0.005)$, which is 0.000 . The implication of aforementioned difference becomes obvious at this point, as the coefficient of AveTP is found below $\alpha(0.005)$, which is 0.000 , compared to that of AveLP at 0.587 . This demonstrates that only AveTP significantly contributes to $\mathrm{KCE}$ in the reading instruction. To see which indicator is actually contributive to $\mathrm{KCE}$, a second multilinear regression analysis was carried out.

According to the multilinear regression analysis, the Adjusted R2 reaches 0.711 ; thus about $71.1 \%$ of the variation in $\mathrm{KCE}$ is explained by the indicators of multidimensional learning processes. In addition, the regression equation seems to be substantially helpful for making predictions as the value of $\mathrm{R} 2$ is close to 1 . To further confirm this test, the result of ANOVA evinces the explanatory power of each predictor to knowledge creation self-efficacy in the reading instruction.

H0: $\beta=0$, meaning the indicators are not useful to predict $\mathrm{KCE}$.

Ha: $\beta \neq 0$, meaning the indicators are useful to predict KCE.

Given $\alpha=0.05$, the analysis demonstrates that $\mathrm{p}$ value (0.000) is well below 0.05 and therefore confirms that null hypothesis is turned down, implying that at least one of the indicators (predictors) possesses robust explanatory power toward KCE. Looking at individual indicators of multidimensional learning processes, the analysis has found that several indicators, across four dimensions distributed in both learning processes and thinking processes, are markedly contributive to KCE. These include MLT3 with p-value 0.003, CriT2 with pvalue 0.001 , CriT3 with p-value 0.001 , CreT4 with pvalue 0.000 , and APS with p-value 0.019 .

The fact that no indicators of $\mathrm{CoL}$ and SDL contribute to KCE highlights the need for teachers to encourage the students, who may tend to be driven by performance goals, to practice metacognitive strategies for empowering their learning (Coutinho 2007; Theodosiou \& Papaioannou 2006). This can be attributed to the minimum monitoring and coaching on metacognitive strategies on how to plan and arrange their works. Furthermore, teachers need to bring clear strategies for collaborative learning bound to KCE. From the observation, the teachers applied conventional group discussion with no specific structure or goal as indicated by specific assessment batteries.

Referring to Chai's (2015) finding on the mediating nature of thinking processes between learning processes and knowledge creation, this study further attempted to scrutinize whether such hierarchical relationship exists when $4 \mathrm{Cs}$ are operative in reading instructions and possible magnitude of learning processes toward thinking process. To this end, another multilinear regression analysis was at work, producing adjusted R2 0.674 and $\mathrm{p}<0.01$. When the coefficient value is taken into account, three indicators of learning processes are found to have $\mathrm{p}<0.01$. These are SDL 2 (In this class, I set goals for my studying), MLT 3 (In this class, I use the computer to remix/reorganize information from other resources), and MLT 4 (In this class, I construct ICT-based materials, e.g., PowerPoint slides, word documents, mindmaps, to represent my understanding), with $\beta$ values of $0.262,0.225$, and 0.292 respectively.

This regression model seems to be more robust and empirically grounded than the reverse model. Another multilinear regression analysis is carried out to see if learning processes can be attributed to the thinking process, which generates R2 0.612 and $p$ $<0.01$. Only one indicator of thinking processes can 
predict learning process, which is CriT1 with $\beta=0.240$. Again, this finding acknowledges Chai's (2015) original model on the relationship between these domains. Learning processes need to be triggered by complex tasks designed and, more importantly, monitored by teachers to lead to higher-order thinking skills. To sum up, the more students are engaged in complex learning processes, the more they activate required thinking processes essential to knowledge creation. That being said, it is imperative that teachers be both creative and critical in designing learning activities to activate and foster students' thinking processes.

This, to some extent, implies why none of the indicators corresponding to SDL and CoL can predict KCE; structured collaboration and scaffolding by teachers have been insufficient. Pondering both SDL and CoL, teacher can give feedback which emphasizes the use of proper strategies instead of efforts to ensure that learning is devoted to improving strategic tasks (Ee \& Atputhasamy, 2002). Cantwell \& Andrews (2002) found that, regardless of the inclination to either mastery or performance goals, students prefer group learning, which results in higher rates of metacognitive awareness and positive achievement goals. Some of the examples of collaborative reading to hone both cognitive and metacognitive performance include buddy reading, literature circles, think-pair-share, and digital book clubs. To scaffold SDL and CoL for high literacy particularly among university students, literature circles can be one apt option in this respect. Thein, Guise, \& Sloan (2011) argue that literature circles, with scaffolding, modeling, and guiding by teachers, can be powerful repertoire for literacy teachers to engage students in multicultural and political texts when critical literacy is the goal.

\section{Students' voices on their multidimensional learning processes in $4 \mathrm{Cs}$ reading instruction}

To answer the third research question and obtain finecut insights into the impact of 4Cs approach in reading instruction to students' learning experiences, The following results of focus group discussion further probed into the students' voices. Random sampling was performed in determining the participants in the discussion. Based on the analysis results, three main themes came to surface; 1) 4Cs Approach scaffolds creative and critical thinking skills, 2) 4Cs Approach fosters achievement goals and social goals, and 3) 4Cs Approach creates mind-provoking and exhilarating transactional reading.

\section{Theme 1: 4Cs Approach scaffolds creative and critical thinking skills}

With regard to student's higher-order thinking skills involving creative thinking and critical thinking skills, it is obvious that $4 \mathrm{Cs}$ approach to reading instruction enables teachers to accrue motivation to strive towards higher-order thinking as everyone in the class is challenged to come up with their own personalized ideas relative to various learning tasks and objectives.
The following excerpt of a student's response in the FGD corroborates the findings.

"Being involved in collaborative learning allowed me to come up with numerous ideas to contribute to the group discussion and at the same time expose me to abundance of ideas. This, as a result, helped me to think beyond what I knew and expanded my point of view". [Research subject 5]

Another student also puts forward similar learning experience, particularly characterized by high literacy driven by dialogic space.

"There was an obviously wide range of competences among the group members, and sometimes some students were dominant over the others. However, this difference helped everyone to see things from different perspectives and thus encourage critical thinking to gain shared understanding”. [Research subject 1]

The abovementioned voices have robustly evinced that $4 \mathrm{C}$ can be one apt alternative for the teacher to orchestrate learning experience where everyone is worth appreciating. This positive sociocultural atmosphere nullifies the sense of guilt, underperformance, and also shame inasmuch as everyone is accorded with equal opportunity to take part in learning process.

\section{Theme 2: 4Cs Approach fosters achievement goals and social goals}

"One particular difficulty in the learning process was when only one student expressed his idea, while the rest was not really sure of their own ideas or simply had different idea. We learnt from our collaborative learning that nobody was underrated. First, we were encouraged to mitigate differences amongst group members by further discussion and tried to come up with one joint understanding. Second, those who had no ideas on matter being discussed were able to learn from their peers." [Research subject 3]

"Another great thing I got from the learning process was
a soft skill, teamwork. It was obvious that group work
helped me to reshape and refine my ideas as everyone
was invited to contribute ideas. What was more
important was that there was no right-or-wrong
judgment in my team; everyone's idea was appreciated.
The group member helped one another as we had
different levels of vocabulary mastery. This gave us a
sense of security and appreciation and helped us to gain
deeper understanding".[Research subject 6]

Since everyone was propelled to excel at, assumedly, similar level, the 4Cs approach scaffold the idea that everyone has the hope of success, concomitantly nullifying the fear of failure. The group work thus becomes a catalyst to everyone's learning. The abovementioned vignettes show that the students were driven by a mastery approach as they were concerned with how they could achieve and contribute to the group discussion. The approach upholds the values of collaborative learning for shared success, rather than putting students in competitive learning environment, which is why performance approach is not evident. 


\begin{abstract}
"At the end of group discussion, every group assigned one representative to come forward and presented the result of group discussion. There were some differences among the groups, yet that was not a problem. We learnt to appreciate others' ideas and, more importantly, acknowledge and value individual differences". [Research subject 1]
\end{abstract}

The student's voice acknowledges the social concern in the learning process. The absence of competition results in a positive classroom atmosphere where students work in tandem to accomplish the tasks. As both achievement and social goals are significant predictors to learning enjoyment and metacognition, this infers that the multidimensional learning goals in $4 \mathrm{Cs}$ approach do emerge enjoyment as students are not only encouraged to achieve in the class but also to socialize through collaborative work (Ee, Wang, Kon, Tan, \& Liu, 2009). Shared reading aimed at high literacy may have empowered the students to be more reflective since they try to evaluate the quality of their work and subsequently synthesize for their group report and oral presentation. In terms of social concern, students concerned with assisting their peers can also benefit from applying high literacy.

The sense of security and equal collaboration in class allowed the students to choose the strategies for authentic problem-solving and encouraged them to be adaptive to achieving their learning goals. Chai et al. (2015) avers that being adaptive constitutes a pivotal foundation to lifelong learning for learners to be able to learn and relearn when new tasks emerge. In the same vein, the collaborating-to-learn element in $4 \mathrm{Cs}$ approach, calling for collaboration, communication, and social skills, has resulted in the collective process of establishing productive learning community and progressive discourse. As students involved in communication and negotiation, they formulate and revise agreeable criteria for evaluating and offering solutions to differences amongst ideas (Scardamalia, 2002). The learning-to-learn part of 4Cs clearly has come to its element as the students are liberated to negotiate and refine their ideas, further empowering them to develop socially, cognitively, and metacognitively (Scardamalia, 2002).

\section{Theme 3: 4Cs Approach creates mind-provoking and exhilarating transactional reading}

As aforementioned, soft skill has been proven equally important element in 4Cs-grounded learning. The sense of collaboration and communication inculcates positive intercultural communication among learners and thus they are liberated to actualize themselves, either as learner or individual. The sense of intercultural communication competence lays pivotal cornerstone in establishing positive classroom emotion. When classroom atmosphere is supportive of learning, students are accorded with the liberty to think creatively and critically, both as an individual and as a team. The following excerpt is indicative of this premise.

\begin{abstract}
"At one point, everyone was involved in the discussion to determine the ending of a story. Of course, we came up with different ideas; some might have the same ideas. This difference challenged us to think of what might be the best ending of the story. We needed to determine unique ending, yet at the same time relevant to the original story. So yeah it was challenging, yet exciting at the same time". [Research subject 2]
\end{abstract}

The challenge in creating a novel ending of a story triggers students' creative and critical thinking. This is indicative of students being encouraged to analyze contexts, evaluate opinions, make decisions, and solve authentic problems (Elder \& Paul, 1994). Students are not only challenged to come up with ideas to complete the story but, most importantly, also fostered to examine each other's ideas along with the supporting evidence or rationales. Essentially, discursive collaboration empowers the students to scrutinize and challenge proposed ideas with alternatives for idea improvement (P21CS, 2009). The following figure points out the framework comprising of socio-constructivist the theory, transactional reading theory, and $4 \mathrm{Cs}$.

The findings from the FGD clearly sheds light on how 4Cs approach to reading instruction helps students to grow and maintain multidimensional competencies in their learning process. Figure 2 depicts the overall findings concerning how the $4 \mathrm{Cs}$ approach to reading escalates students' multidimensional learning competencies. On epistemological ground, 4Cs can be atomized into two dominant components, comprising of social-connectedness facets (communication and collaboration) and cognitive-connectedness facets (creative thinking and critical thinking). These components are embedded in social interaction and literacy transactions, respectively. Instead of being the ultimate target of learning process, literacy bridges the reciprocity between social interaction and literacy transactions, which results in escalated multidimensional learning competencies. The major contribution of the present study is that it translates the $4 \mathrm{Cs}$ of $21 \mathrm{st}$ century learning into Sociocognitive learning theories and Transactional reading theory actualized in instructional scaffolding and highlights contextual frameworks which propel reading, writing, and discourse for joint meaning-making.

Deploying the 4Cs approach in reading instruction engages students in cooperative learning to discuss literacy transactions, which concomitantly creates context supportive to the use of reading strategies empowering everyone through scaffolding. As such, English is used for authentic meaningful purposes. The findings acknowledge Rosenblatt's contention (2001) that reading is not merely a process of coding words, yet rather transactional undertaking involving readers and texts. This approach is substantial to lay robust cornerstone to accruing positive classroom atmosphere where everyone is given equal emphasis and equally appreciated, regardless of their initial competence and background. When everyone is given equal appreciation, everybody is fostered to excel at high 
level. The sense of ZPD does come to its element in this regard. The more capable students can improve themselves by helping their peers to improve through generating and explaining different ideas to different peers, while the less-able learners benefit from the assistance given from their friends. This learning-tolearn perspective helps students to not only achieve their objectives but also enhance the objectives throughout their learning process. This finding is in line with Sontag's premise (2009) germane to his work on SCCS (social and cognitive connectedness schemata). Sociocognitive-laden learning community helps teacher and students to mitigate the gap between high achievers and low achievers and concomitantly enhances students' learning transfer abilities. Stemming from socioconstructivist spectacles, the study has acknowledged that (high) literacy is best taught through dialogic process, which involves reading, writing, listening, and speaking by which learners are enabled to negotiate new understanding. Language, i.e. literacy, plays pivotal role in learning process not only as the subject matter but also as the medium of students-students and teacherstudents' metacognitive orchestra through which meaning is shared among individuals (Gee, 2001; Haneda \& Wells, 2000; Karpov \& Haywood, 1998; Pressley, 2000; Wilkinson \& Silliman, 2000).

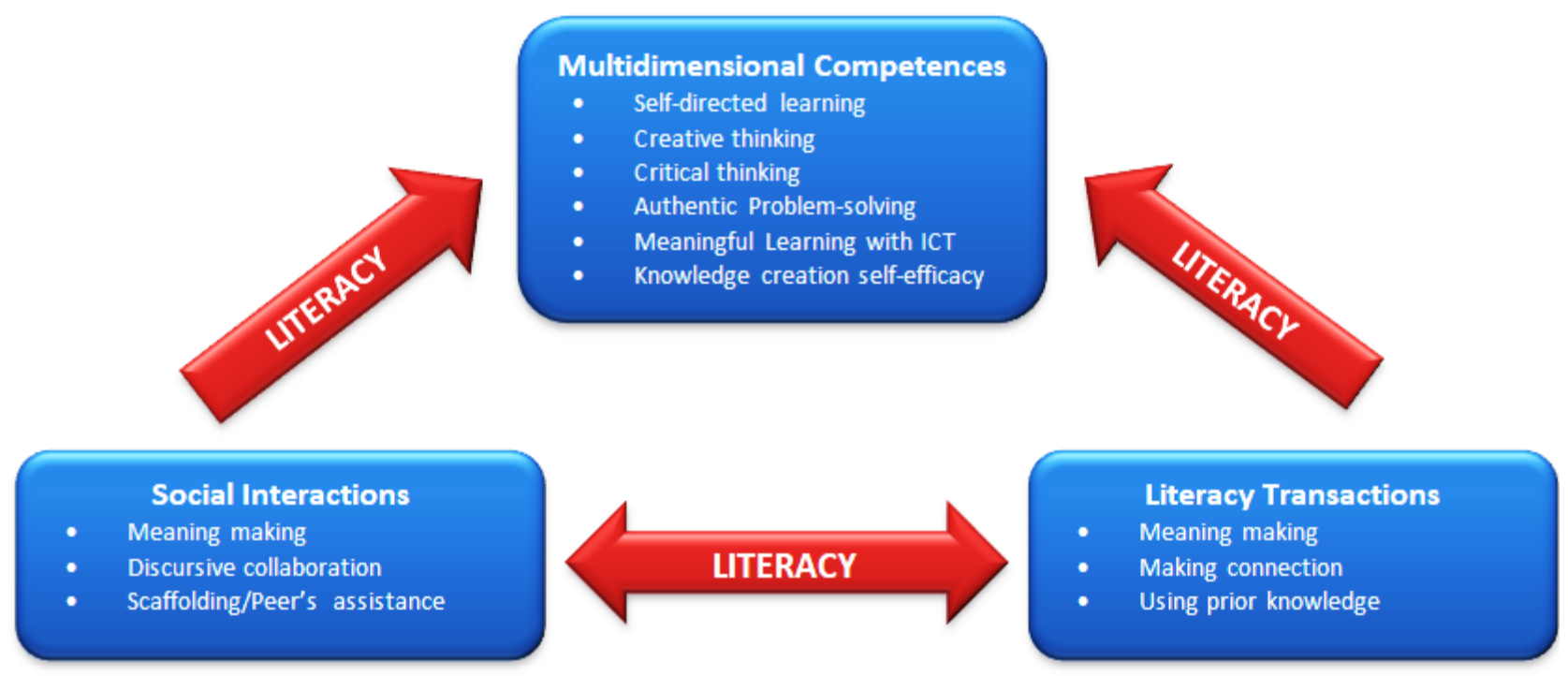

Figure 2. The reciprocity between social interaction and literacy transactions to enhance multidimensional competences

\section{CONCLUSION}

4Cs approach is proven substantial to help both teacher and students to grow and maintain a positive classroom atmosphere. This is indicative of students' positive collaboration where everyone is appreciated and given equal opportunity to gain high literacy. As learning processes set the bedrock to thinking processes, teachers need to put substantial concern in the design and goals of collaborative work to robustly proper thinking processes for high literacy. This study suggests that employing the instructional strategy which taps upon students' social-connectedness and cognitiveconnectedness schemata aids in establishing and fostering positive classroom atmosphere, which leads to increased academic performance and better self-efficacy for high literacy. The discursive collaboration will help students to advance their multi-perspective thinking and challenge them to solve real-world problems. This study has corroborated the existing works which have acknowledged that self-efficacy, triggered and amplified through discursive collaboration imbued with 4Cs, inculcates positive outlooks on life and, therefore, propels learners to continually strive for both achievement and social goals beyond what they have actually achieved. One key limitation to the study is that it does not investigate students' voices on the difficulties students encounter when engaged in 4Cs reading class. Such insight obviously lends itself to explaining possible social and psychological barriers to students' efforts which may hamper them from achieving. By extension, this potential calls forth the investigation on apt strategies teachers can deploy to cope with subsequent mastery and/or performanceavoidance goals.

\section{ACKNOWLEDGMENT}

The present study is made possible by the 2018 research grant awarded by University of Jember for LATEM research group.

\section{REFERENCES}

Alexander, P. A., \& Jetton, T. L. (2000). Learning from text: A multidimentional and developmental perspective. In M. L. Kamil, P. B. Mosenthal, P. D. Pearson, \& R. Barr (Eds.), Handbook of reading research (Vol. 3, pp. 269-284).Mahwah, NJ: Lawrence Erlbaum.

Alfassi, M. (2009) The efficacy of a dialogic learning environment in fostering literacy. Reading 
Psychology, 30(6), 539-563, doi: 10.1080/02702710902733626

Applebee, A. N., Langer, J., Nystrand, M., \& Gamoran, A. (2003). Discussion based approaches to developing classroom instruction and student performance in middle and high school English. American Educational Research Journal, 40, 685730.

Bereiter, C., \& Scardamalia, M. (2006). Education for the knowledge age. In P. A. Alexander \& P. H. Winne (Eds.), Handbook of educational psychology (2nd ed., pp. 695-713). Mahwah, NJ: Lawrence Erlbaum.

Bromley, K. Faughnan, M. Ham, S. Miller, M. Armstrong, T. Crandall, C. Garrison, J. \& Marrone, N. (2014). Literature Circles Go Digital. The Reading Teacher, 68(3 ), 229-236. doi: $10.1002 /$ trtr.1312

Brown, J. S., A. Collins, \& P. Duguid. (1989). Situated learning and the culture of learning. Education Researcher, 18(1), 32-42.

Bransford, J. D., Brown, A. L., \& Cocking, R. R. (2005). How people learn: Brain, mind, experience and school (Expanded edn.). Washington, DC: National Academy Press.

Braun, V., \& Clarke, V. (2006). Using thematic analysis in psychology. Qualitative Research in Psychology, 3, 77-101.

Cantwell, R. H., \& Andrews, B. (2002). Cognitive and psychological factors underlying secondary school work students' feelings towards group work. Educational Psychology, 1, 75-92. doi: 10.1080/01443410120101260.

Cahyono, B. Y. \& Widiati, U. (2006). The teaching of EFL reading in the Indonesian context: The state of the art. TEFLIN Journal, 17(1), 36-58.

Chai, C. S., Koh, J. H. L., Deng, F., Tsai, P., \& Tsai, C. (2015). Assessing multidimensional students' perceptions of twenty-first-century learning practices. Asia Pacific Education Review, 16(3). doi: 10.1007/s12564-015-9379-4

Coutinho, S. A. (2007). The relationship between goals, metacognition, and academic success. Educate,7(1), 39-47.

Dowson, M., \& McInerney, D. M. (2003). What do students say about their motivational goals? Towards a more complex and dynamic perspective on student motivation. Contemporary Educational Psychology, 28, 91-113. doi:10.1016/S0361476X(02)00010-3.

Ee, J., \& Atputhasamy, L. (2002). Differences in teacher feedback for HA and LD students. Teaching \& Learning, 23(1), 1-12.

Ee, J, Wang, C. K. J., Koh, C. Tan, O. S., \& Liu, W. C. (2009). Goal orientations and metacognitive skills of normal technical and normal academic students on project work. Asia Pacific Education Review, 10, 337-344. doi: 10.1007/s12564-009-9033-0
Elder, L., \& Paul, R. (1994). Critical thinking: Why we must transform our teaching. Journal of Developmental Education, 18(1), 34-35.

Garrison, D. R. (1992). Critical thinking and selfdirected learning in adult education: An analysis of responsibility and control issues. Adult Education Quarterly, 42(3), 136-148.

Gee, J. P. (2001). Reading as situated language: A sociocognitive perspective. Journal of Adolescent and Child Literacy, 44, 714-725.

Gill, S., \& Islam, C. (2011). Shared reading goes hightech. The Reading Teacher, 65(3), 224-227.

Griffin, P., MacGaw, B., \& Care, E. (2012). Assessment and teaching of 21 st century skills. Heidelberg: Springer.

Haneda, M., \& Wells, G. (2000). Writing in knowledge building communities. Research in the Teaching of English, 34(3), 430-457.

Kant, I. (1998). Critique of pure reason (Guyer, P. \& Wood, A. W., Trans.). Cambridge: The Press Syndicate of The University of Cambridge

Kim, H. (2016): The relationships between Korean university students' reading attitude, reading strategy use, and reading proficiency. Reading Psychology, 37, 1162-1195. doi: 10.1080/02702711.2016.1193581

International Society for Technology in Education (ISTE). (2013). The national educational technology standards (NETS).Available online at http://www.iste.org/standards. Accessed on 1 November 2018.

Jonassen, D. H. (2000). Towards a design theory of problem. Educational Technology Research and Development, 48(4), 63-85.

Karpov, Y. V., \& Haywood, H. C. (1998). Two ways to elaborate Vygotsky's concept of mediation: Implications for instruction. American Psychologist, 53(1), 27-36.

Oblinger, D., \& J. Oblinger. (2005). Is it age or IT: First steps toward understanding the net generation. In D. Oblinger \& J. Oblinger (eds.), Educating the net generation. Retrieved from http://www.educause.edu/educatingthenetgen (accessed February 5, 2019).

Organisation for economic co-operation and development (OECD). (2005). The definition and selection of key competences. Available online at http://www.oecd.org/pisa/35070367.pdf. Accessed 1 December 2018.

Partnership for 21st Century Skills. (2009). Framework for 21 st century learning. Available online at http://www.p21.org/documents/P21_Framework.p df. Accessed 1 December 2018.

Piaget, J. (1976). Postface. Archives de Psychologie, 44, 223-28

Pressley, M. (2000). What should comprehension instruction be the instruction of? In M. L. Kamil, P. B. Mosenthal, P. D. Pearson, \& R. Barr (Eds.), Handbook of reading research (Vol. 3, pp. 545563). Mahwah, NJ: Lawrence Erlbaum. 
Rosenblatt, L. M. (2001). The literary transaction: Evocation and response. Theory into Practice, XXI(4), 268-277.

Scardamalia, M. (2002). Collective cognitive responsibility. In B. Smith (Ed.), Liberal education in the knowledge age (pp. 76-98). Chicago: Open Court.

Smagorinsky, P. (2001). If meaning is constructed, what is it made from? toward a cultural theory of reading. Review of Educational Research, 71(1), 133-169.

Sontag, M. (2009). A learning theory for 21st-century students. Innovate: Journal of Online Education, 5(1). $1-10$

Thein, A. H., Guise, M, \& Sloan, D. L. (2011). Problematizing literature circles as forums for discussion of multicultural and political texts. Journal of Adolescent \& Adult Literacy, 55(1), 1524. doi:10.1598/JAAL. 55.1.2

Theodosiou, A., \& Papaioannou, A. (2006).

Motivational climate, achievement goals and metacognitive activity in physical education and exercise involvement in out-of-school settings. Psychology of Sport and Exercise, 7(4), 361-379.

Urdan, T. C., \& Maehr, M. L. (1995). Beyond a two goal theory of motivation and achievement: A case for social goals. Review of Educational Research, 65, 213-243

Wilkinson, L. C., \& Silliman, E. R. (2000). Classroom language and literacy learning. In M. L. Kamil, P. B. Mosenthal, P. D. Pearson, \& R. Barr (Eds.), Handbook of reading research (Vol. 3, pp. 337360). Mahwah, NJ: Lawrence Erlbaum.

Vygotsky, L. S. (1978). Mind in society: Development of higher psychological processes. Cambridge, MA: Harvard University Press.

Yamashita, J. (2007). The relationship of reading attitudes between L1 and L2: An investigation of adult EFL learners in Japan. TESOL Quarterly, 4l(1), 81-105.

Zimmerman, B. J. (2008). Investigating self-regulation and motivation: Historical backgrounds, methodological developments, and future prospects. American Educational Research Journal, 45(1), 166-183. 